\title{
Armazenamento de maçã 'Gala' em atmosfera controlada com remoção de etileno
}

\author{
Storage of 'Gala' apple in controlled atmosphere with removal of \\ ethylene
}

\author{
Auri Brackmann ${ }^{1}$ Cristiano André Steffens ${ }^{2}$ \\ Daniel Alexandre Neuwald ${ }^{3}$ Ivan Sestari $^{4}$
}

\section{RESUMO}

$O$ objetivo deste trabalho foi avaliar o efeito de diferentes níveis de etileno na câmara sobre a manutenção da qualidade da maçã cv. Gala, durante o armazenamento em AC. $O$ delineamento experimental utilizado foi inteiramente casualizado com quatro repetições e a unidade experimental composta por 50 frutos. Os tratamentos utilizados foram: $>10 \mu l L^{-1}$ (sem absorção); <0,4 $\mu l L^{-1} e<0,04 \mu l L^{-1}$, cujos níveis mais baixos foram obtidos por absorção química. Após oito meses de armazenamento, na abertura das câmaras e após sete dias a $20^{\circ} \mathrm{C}$, verificou-se maior firmeza de polpa, maior acidez titulável e menor ocorrência de podridões e degenerescência senescente nos frutos armazenados com remoção do etileno. Quanto aos teores de sólidos solúveis totais, não houve diferença estatística entre os tratamentos, em ambas as avaliações. A coloração da epiderme apresentou-se mais verde nos frutos armazenados sob remoção de etileno, após sete dias de exposição dos frutos a $20^{\circ} \mathrm{C}$. A incidência de polpa farinhenta foi menor nos tratamentos com eliminação do etileno, na abertura das câmaras.

Palavras-chave: conservação, pós-colheita, distúrbios fisiológicos.

\section{ABSTRACT}

The objective purpose of this work was to evaluate the effect of different ethylene levels on the quality of $c v$. Gala apples during CA storage. The experimental design was completely randomized with 4 replications of 50 fruits. The treatments were: $>10 \mu l L^{-1}$ (without absorption); $<0.4 \mu l L^{-1}$ and $<0.04 \mu \mathrm{l} \mathrm{L} \mathrm{L}^{-1}$. After 8 month storage, at the chambers opening and after 7 days shelf life at $20^{\circ} \mathrm{C}$ fruits with ethylene absorption had higher firmness and titratable acidity and lower rot and senescent breakdown incidence. There was no statistic difference between treatments for TSS. After 7 days shelf life ground color was greener on the fruits stored with ethylene absorption. Mealy fruits incidence was lower with ethylene absorption, at the chambers opening.

Key words: conservation, postharvest, physiological disorders.

\section{INTRODUÇÃO}

O armazenamento de maçãs é uma prática comum no Brasil, sendo que atualmente $56 \%$ do volume armazenado e ocorre sob o sistema de atmosfera controlada (AC). A cultivar Gala apresenta um bom potencial de armazenamento em AC, no entanto, altas quantidades de etileno acumulam na atmosfera da câmara frigorífica, que, além de estimular sua própria síntese, pelo mecanismo de autocatálise, aceleram o amadurecimento dos frutos. Segundo BRACKMANN \& SAQUET (1999), a remoção do etileno do ambiente de armazenamento, melhora ainda mais a conservação e a qualidade da maçã 'Gala', aumentando o tempo de armazenamento da fruta. Estima-se um aumento no tempo de armazenamento de 30 a 45 dias com a remoção do etileno.

Obviamente a eficácia desta técnica está condicionada à eficiência do equipamento removedor

\footnotetext{
${ }^{1}$ Engenheiro Agrônomo, Doutor, Departamento de Fitotecnia, Centro de Ciências Rurais (CCR), Universidade Federal de Santa Maria (UFSM), 97105-900, Santa Maria-RS. E-Mail:brackmann@creta.ccr.ufsm.br

${ }^{2}$ Engenheiro Agrônomo, Acadêmico do Programa de Pós-graduação em Agronomia da UFSM, Bolsista CAPES.

${ }^{3}$ Acadêmico do cruso de Agronomia da UFSM, Bolsista PIBIC/CNPq.

${ }^{4}$ Acadêmico do cruso de Agronomia da UFSM, Bolsista CNPq.
} 
do gás em manter a concentração de etileno, na atmosfera da câmara, inferior à concentração fisiologicamente ativa. Por exemplo, em kiwi armazenado a $0^{\circ} \mathrm{C}$, uma concentração igual ou maior a $0,1 \mu \mathrm{L} \mathrm{L}^{-1}$ é suficiente para desencadear o processo de amadurecimento (HARRIS, 1981). Entretanto, CACIOPPO (1989) obteve melhoria significativa na conservação do kiwi, mantendo a concentração de etileno inferior a $0,025 \mu \mathrm{L} \mathrm{L}^{-1}$. BRACKMANN et al. (2000a) verificaram que, quanto mais baixa a concentração de etileno durante o armazenamento da maçã cultivar Royal Gala, maior é a retenção da firmeza de polpa, sendo que, para os demais atributos de qualidade, concentrações inferiores a $1 \mu \mathrm{L} \mathrm{L}^{-1}$ apresentam efeito semelhante.

O conhecimento da concentração crítica de etileno é de extrema importância, visto que alguns produtores de maçãs utilizam um mesmo equipamento absorvedor para até três câmaras frigoríficas, tentando um melhor aproveitamento do equipamento. Entretanto, esta prática diminui a eficiência do absorvedor na eliminação do gás, podendo a concentração de etileno, dentro da câmara frigorífica, atingir o nível fisiologicamente ativo.

Desta forma, o objetivo deste trabalho foi avaliar o efeito de níveis de etileno sobre a manutenção da qualidade da maçã cv. Gala armazenada em AC.

\section{MATERIAL E MÉTODOS}

O experimento foi conduzido no Núcleo de Pesquisa em Pós-colheita (NPP) do Departamento de Fitotecnia da Universidade Federal de Santa Maria, RS. Os frutos da cultivar Gala foram colhidos num pomar comercial pertencente à empresa Renar Maçãs S.A., localizada em Fraiburgo, SC. Ainda na empresa, os frutos foram selecionados e classificados, utilizandose o calibre 135. Após o transporte dos frutos ao NPP/ UFSM em Santa Maria, procedeu-se nova seleção, eliminando-se os frutos com lesões e/ou defeitos. Posteriormente foram homogeneizadas as amostras experimentais. O delineamento experimental utilizado foi o inteiramente casualizado com quatro repetições de 50 frutos. No momento da instalação do experimento, os frutos possuíam os seguintes parâmetros de maturação: índice iodo-amido 5,46 (escala 1 a 10); firmeza de polpa 77,8N; sólidos solúveis totais (SST) 10,6 $6^{\circ}$ Brix; acidez titulável $6,87 \mathrm{cmol} \mathrm{L}^{-1}$.

Para o armazenamento dos frutos foram utilizadas minicâmaras experimentais de AC, com volume de 232 litros, as quais foram conectadas por tubulações plásticas a uma mesa de controle com analisadores de $\mathrm{O}_{2}$ e $\mathrm{CO}_{2}$. As minicâmaras permaneceram no interior de uma câmara frigorífica com a temperatura controlada em $0^{\circ} \mathrm{C}$.

O monitoramento da temperatura foi realizado diariamente, utilizando-se termômetros introduzidos na polpa de frutos, havendo uma oscilação de $\pm 0,2^{\circ} \mathrm{C}$. A umidade relativa (UR), determinada semanalmente com um psicrômetro, foi mantida em torno de $96 \%$ em todos os tratamentos. A condição de AC adotada foi $1 \mathrm{kPa} \mathrm{O}_{2}$ e $3 \mathrm{kPa} \mathrm{CO}_{2}$. Para a manutenção constante dos níveis de $\mathrm{O}_{2}$ e $\mathrm{CO}_{2}$, que continuamente se modificavam em funçã̃o do processo respiratório dos frutos, foi realizada diariamente uma análise e correção das pressões parciais dos gases. Esta análise foi feita por meio de um sistema de controle da concentração de gases automatizado, equipado com analisadores eletrônicos de $\mathrm{O}_{2}$ e $\mathrm{CO}_{2}$, marca Kronenberger, pelos quais circulou-se uma amostra da atmosfera de cada câmara que, após a análise, retornou à respectiva câmara. $\mathrm{O}_{2}$ consumido pela respiração foi reposto através da injeção de ar atmosférico nas minicâmaras. $\mathrm{O} \mathrm{CO}_{2}$ em excesso foi absorvido por uma solução de hidróxido de potássio $(40 \%)$, através da qual foram circulados os gases das minicâmaras.

Os tratamentos avaliados foram diferentes concentrações de etileno no ambiente da câmara frigorífica $\left(>10 \mu \mathrm{L} \mathrm{L}^{-1} ;<0,4 \mu \mathrm{L} \mathrm{L}^{-1} ; \mathrm{e}<0,04 \mu \mathrm{L} \mathrm{L}^{-1}\right)$. Para a eliminação de etileno, foi realizada a absorção química deste gás por meio de um filtro contendo substrato com permanganato de potássio. $\mathrm{O}$ ar da câmara foi constantemente circulado pelo filtro com uma bomba de membrana com fluxo de $240 \mathrm{~L} \mathrm{~h}^{-1}$, de modo que a concentração de etileno ficou abaixo de $0,04 \mu \mathrm{L} \mathrm{L}^{-1}$. Para a concentração $<0,4 \mu \mathrm{L} \mathrm{L} \mathrm{L}^{-1}$, a bomba foi acionada através de temporizador, o qual foi regulado para manter esta concentração de etileno na câmara. No tratamento sem eliminação de etileno, a concentração foi estabelecida através da síntese do gás pelos próprios frutos, como acontece em câmaras de AC comerciais, onde a concentração pode oscilar entre 10 e $200 \mu \mathrm{L} \mathrm{L}^{-1}$. As determinações de etileno foram realizadas semanalmente por cromatografia gasosa, injetando-se $1 \mathrm{~mL}$ de gás da atmosfera de cada câmara em um cromatógrafo a gás, marca Varian, equipado com detector de ionização de chama, coluna empacotada com Porapak $\mathrm{N}$ de $0,70 \mathrm{~m}$ de comprimento e, como gás de arraste foi utilizado o nitrogênio. As temperaturas empregadas foram $90^{\circ} \mathrm{C}, 140^{\circ} \mathrm{C}$ e $200^{\circ} \mathrm{C}$ para coluna, injetor e detector, respectivamente.

Após oito meses de armazenamento, metade das quatro amostras de 50 frutos foram analisadas no dia da abertura das câmaras e a outra metade das quatro amostras, após sete dias de exposição dos frutos à temperatura de $20^{\circ} \mathrm{C}$, numa câmara de climatização. Para cada tratamento foi calculada a média e a variância para 
os parâmetros avaliados, sendo as médias comparadas pelo teste de Duncan em nível de $5 \%$ de probabilidade de erro. O delineamento experimental utilizado foi o inteiramente casualizado com quatro repetições.

As variáveis avaliadas foram: teste iodoamido (somente analisado na instalação do experimento), firmeza de polpa, sólidos solúveis totais (SST), acidez titulável, podridões, polpa farinhenta e degenerescência senescente, conforme metodologia descrita em BRACKMANN \& SAQUET (1995). Para a determinação da coloração de fundo da epiderme foi utilizado um colorímetro, marca MINOLTA, modelo CR310 , com a leitura de cores pelo sistema tridimensional CIE L* a* b*. O eixo "a" avalia a cor do fruto do verde ao vermelho e o eixo "b" da cor azul ao amarelo. Os resultados de cor foram expressos em $\mathrm{a}^{*}+\mathrm{b}^{*}$.

\section{RESULTADOS E DISCUSSÃO}

A firmeza de polpa, na abertura das câmaras e após sete dias a $20^{\circ} \mathrm{C}$, foi mais elevada nos frutos armazenados com remoção do etileno $\left(<0,4 \mu \mathrm{L} \mathrm{L}^{-1} \mathrm{e}\right.$ $<0,04 \mu \mathrm{L} \mathrm{L}^{-1}$ ) (Tabela 1). BRACKMANN \& SAQUET (1999) também verificaram a eficiência da remoção do etileno durante o armazenamento de maçã 'Gala', na manutenção da firmeza de polpa. A perda de firmeza, segundo LELIÉVRE et al. (1997), é um processo conhecido do amadurecimento que é muito sensível ao etileno e a concentração para induzir a perda de firmeza é menor do que para induzir a respiração (PRATT, 1975) e as mudanças nos pigmentos (BANGERTH, 1975). BRACKMANN et al. (2000a) observaram que, na cultivar Royal Gala, concentrações de etileno próximas a $<0,4 \mu \mathrm{L} \mathrm{L}^{-1}$ já são suficientes para acelerar a degradação da firmeza de polpa.

Os sólidos solúveis totais (SST) não foram influenciados pelas diferentes concentrações de etileno, seja na saída da câmara, seja após sete dias a $20^{\circ} \mathrm{C}$ (Tabela 1). BRACKMANN et al. (2000b) também não verificaram efeito da remoção de etileno sobre os SST da maçã 'Gala'. Entretanto, em 'Royal Gala', a eliminação de etileno proporcionou os menores valores de SST (BRACKMANN et al., 2000a). Estes autores acreditam que este resultado esteja relacionado ao menor acúmulo de açúcares decorrente da hidrólise de amilopectinas e pela degradação da protopectina.

A manutenção do etileno em níveis inferiores $\mathrm{a}<0,4 \mu \mathrm{L} \mathrm{L}^{-1}$ manteve a acidez dos frutos mais elevada, entretanto, após sete dias a $20^{\circ} \mathrm{C}$ não foi observada diferença estatística entre os tratamentos (Tabela 1). BRACKMANN (1991) observou que a remoção do etileno diminuiu a perda de ácidos em maçãs. Segundo TRUTER \& COMBRINK (1993), o armazenamento em $\mathrm{AC}$, juntamente com a redução dos níveis de etileno nas câmaras, diminui a respiração, contribuindo para a obtenção de um elevado conteúdo de ácidos orgânicos após longos períodos de conservação dos frutos.

A coloração de fundo da epiderme, na saída da câmara, não apresentou diferença entre os tratamentos. Entretanto, após 7 dias, os frutos armazenados com eliminação de etileno apresentaram-se mais verdes (Tabela 1). BRACKMANN et al. (2000b) não observaram efeito da remoção do etileno sobre a manutenção da cor verde dos frutos. Segundo LELIÉVRE et al. (1997), o início da degradação das clorofilas, durante o amadurecimento dos frutos, pode ser considerado independente do etileno, uma vez que os frutos expostos a diferentes concentrações de etileno apresentaram o mesmo conteúdo de clorofilas. TRUTER \& COMBRINK (1993) afirmaram que o início da queda no conteúdo de clorofila em maçãs não é antecipado pelo etileno, mas depois de iniciado, o etileno aumenta a taxa de degradação.

A ocorrência de podridões, tanto na saída da câmara como após sete dias a $20^{\circ} \mathrm{C}$, foi estatisticamente semelhante entre os tratamentos (Tabela 2), confirmando os resultados obtidos por BRACKMANN \& SAQUET (1999). Segundo ELKAZZAZ et al. (1985), o etileno pode exibir um efeito estimulatório sobre o crescimento de alguns fungos e, conseqüentemente, aumentar a incidência e a

Tabela 1 - Características físico-químicas da maçã 'Gala' após oito meses de armazenamento em atmosfera controlada. Santa Maria-RS, 1999.

\begin{tabular}{|c|c|c|c|c|c|c|c|c|}
\hline \multirow{2}{*}{$\begin{array}{c}\text { Concentração de } \\
\mathrm{C}_{2} \mathrm{H}_{4} \text { na câmara }\left(\mu 1 . \mathrm{L}^{-1}\right)\end{array}$} & \multicolumn{2}{|c|}{ Firmeza de polpa (N) } & \multicolumn{2}{|c|}{ SST $\left({ }^{\circ}\right.$ Brix $)$} & \multicolumn{2}{|c|}{$\operatorname{Acidez}\left(\mathrm{cmol}_{\mathrm{c}} \mathrm{L}^{-1}\right)$} & \multicolumn{2}{|c|}{ Cor $a^{*}+b^{*}$} \\
\hline & $\begin{array}{l}\text { Saída } \\
\text { Câmara }\end{array}$ & 7 dias & $\begin{array}{l}\text { Saída } \\
\text { Câmara }\end{array}$ & 7 dias & $\begin{array}{l}\text { Saída } \\
\text { Câmara }\end{array}$ & 7 dias & $\begin{array}{l}\text { Saída } \\
\text { Câmara }\end{array}$ & 7 dias \\
\hline 10 & $65,19 b^{*}$ & $67,17 \mathrm{~b}$ & $13,05 \mathrm{a}$ & $12,95 \mathrm{a}$ & $4,44 \mathrm{~b}$ & $4,23 \mathrm{a}$ & $41,38 \mathrm{a}$ & $45,95 \mathrm{a}$ \\
\hline$<0,4$ & $75,91 \mathrm{a}$ & $78,50 \mathrm{a}$ & $13,07 \mathrm{a}$ & $13,02 \mathrm{a}$ & $4,79 \mathrm{a}$ & $4,37 \mathrm{a}$ & $40,96 \mathrm{a}$ & $41,46 \mathrm{~b}$ \\
\hline$<0,04$ & $79,31 \mathrm{a}$ & $78,70 \mathrm{a}$ & $12,87 \mathrm{a}$ & $12,85 \mathrm{a}$ & $4,79 \mathrm{a}$ & $4,27 \mathrm{a}$ & 39,61 a & $41,59 \mathrm{~b}$ \\
\hline Média & 73,5 & 74,8 & 13,0 & 12,9 & 4,68 & 4,29 & 40,65 & 43,00 \\
\hline CV $(\%)$ & 5,86 & 3,01 & 1,16 & 1,68 & 4,41 & 2,93 & 3,58 & 4,07 \\
\hline
\end{tabular}

* Tratamentos com médias seguidas pelas mesmas letras não diferem estatisticamente entre si, pelo teste de Duncan em nível de $5 \%$ de probabilidade de erro. 
Tabela 2 - Ocorrência de podridões e distúrbios fisiológicos em maçãs 'Gala' após oito meses de armazenamento em atmosfera controlada. Santa Maria-RS, 1999.

\begin{tabular}{|c|c|c|c|c|c|c|}
\hline \multirow{2}{*}{$\begin{array}{c}\text { Concentração de } \mathrm{C}_{2} \mathrm{H}_{4} \\
\text { na câmara }\left(\mu 1 \mathrm{~L}^{-1}\right)\end{array}$} & \multicolumn{2}{|c|}{ Podridões (\%) } & \multicolumn{2}{|c|}{ Polpa farinhenta (\%) } & \multicolumn{2}{|c|}{ Degenerescência senescente $(\%)$} \\
\hline & Saída Câmara & 7 dias & Saída Câmara & 7 dias & Saída Câmara & 7 dias \\
\hline 10 & $7,5 \mathrm{a}^{*}$ & $15,0 \mathrm{a}$ & $16,7 \mathrm{a}$ & $8,3 \mathrm{a}$ & $16,7 \mathrm{a}$ & $21,7 \mathrm{a}$ \\
\hline$<0,4$ & $3,3 \mathrm{a}$ & $5,8 \mathrm{a}$ & $5,1 \mathrm{ab}$ & $1,9 \mathrm{~b}$ & $14,4 \mathrm{a}$ & $7,7 \mathrm{c}$ \\
\hline$<0,04$ & $0,0 \mathrm{a}$ & $6,7 \mathrm{a}$ & $0,0 \mathrm{~b}$ & $3,9 \mathrm{ab}$ & $5,0 \mathrm{~b}$ & $18,2 \mathrm{~b}$ \\
\hline Média & 4,4 & 9,2 & 2,8 & 4,7 & 9,2 & 15,7 \\
\hline CV $(\%)$ & 50,65 & 38,23 & 74,44 & 36,90 & 26,22 & 12,07 \\
\hline
\end{tabular}

* Tratamentos com médias seguidas pelas mesmas letras não diferem estatisticamente entre si, pelo teste de Duncan em nível de $5 \%$ de probabilidade de erro.

severidade dos danos. Por outro lado, o etileno pode induzir a formação de fitoalexinas ou outros compostos que aumentam a resistência dos frutos aos patógenos. Enzimas, como peroxidases e polifenoloxidases, foram associadas à resistência dos frutos, induzida pelo etileno, ao ataque de patógenos (KADER, 1985).

A incidência de polpa farinácea e degenerescência senescente foram menores nos frutos armazenados com remoção do etileno (Tabela 2). Isto pode ser explicado pelo fato de que a remoção do etileno reduz a degradação dos componentes da parede celular, em especial a protopectina e, com isso, evita a ocorrência de polpa farinácea e degenerescência senescente. Segundo SAQUET (1997), o etileno pode incrementar a incidência de frutos com polpa farinácea por acelerar o amadurecimento, já que este distúrbio ocorre com maior intensidade em condições de armazenamento que favorecem o amadurecimento.

\section{CONCLUSÃO}

A remoção do etileno proporciona frutos com melhores características físico-químicas e níveis mais baixos de podridões e distúrbios fisiológicos, quando comparados com o tratamento sem absorção $\left(>10 \mu \mathrm{L} \mathrm{L}^{-1}\right)$. De forma geral, a redução de etileno a concentrações $<0,4 \mu \mathrm{L} \mathrm{L}^{-1}$ já é suficiente para manter satisfatoriamente a qualidade de frutos.

\section{REFERÊNCIAS BIBLIOGRÁFICAS}

BANGERTH, F. The effect of ethylene on the physiology of ripening of apple fruits at hipobaric conditions. In: Facteurs et régulation de la maturation des fruits, 1974. Paris : Colloques Internationaux du Centre National de la Recherche Scientifique, 1975. n. 238, p.183-188.

BRACKMANN, A. Influência da concentração de oxigênio e etileno sobre a qualidade de maçãs armazenadas em atmosfera controlada. Revista Brasileira de Fruticultura, Cruz das Almas, v.13, n.3, p.235-242, 1991.
BRACKMANN, A.; SAQUET, A.A. Low ethylene and rapid CA storage of 'Gala' apples. Acta Horticulturae, Wageningen, n. 485, p.79-83, 1999.

BRACKMANN, A.; SAQUET, A.A. Armazenamento de maçã cv. Gala em atmosfera controlada. Revista Brasileira de Agrociência, Pelotas, v.1, n.2, p.55-60, 1995.

BRACKMANN, A. et al. Armazenamento de maça 'Royal Gala' sob diferentes concentrações de etileno. Revista Brasileira de Agrociência, Pelotas, v.6, n.1, p.39-41, 2000a.

BRACKMANN, A.; STEFFENS, C.A.; HUNSCHE, M. Influência da instalação das condições de atmosfera controlada e concentração de etileno sobre a qualidade da maçã 'Gala'. Revista Brasileira de Armazenamento, Viçosa, v.25, n.1, p.22-27, 2000b.

CACIOPPO, O. L' Actinidia. Lisboa : Editorial, 1989. 123p.

EL-KAZZAZ, M.D.; SOMMER, N.F.; KADER, A.A. Ethylene effects on postharvest fruit diseases. In: BLANKENSHIP, S.M. (ed.). Controlled atmospheres for storage and transport of perishable agricultural commodities. Raleigh, 1985. p.348-351.

HARRIS, S.; REID, M.S. Techniques for improving the storage life of kiwifruit (Actinidia chinensis). Auckland: Auckland Industrial Development Division, DSIR, 1981. 23p. (Publication G120).

KADER, A.A. Ethylene-induced senescence and physiological disorders in harvested horticultural crops. HortScience, Alexandria, v.20, n.1, p.54-57, 1985.

LELIÈVRE, J. et al. Ethylene and fruit ripening. Physiologia Plantarum, Copenhagen, v.101, p.727-739, 1997.

PRATT, H.K. The role of ethylene in fruit ripening. In: Facteurs et règulation de la maturation des fruits, 1974 . Paris : Colloques Internationaux du Centre National de la Recherche Scientifique, 1975. N.238, p.153-160.

SAQUET, A.A. Efeito das temperaturas e concentrações de $\mathrm{CO}_{2}$ e $\mathrm{O}_{2}$ sobre a qualidade da maçã cultivar Gala durante o armazenamento em atmosfera controlada. 1997. 105f. Dissertação (Mestrado em Agronomia) Universidade Federal de Santa Maria, Santa Maria.

TRUTER, A.B.; COMBRINK, J.C. Ethylene levels in commercial CA and low-ethylene CA storage of Golden Delicious, Starking and Granny Smith apples and Packham's Triumph pears. Tree Fruit Postharvest Journal, Washington, v.4, n.3, p.14-18, 1993. 